\title{
EFFECT OF FRICTION IN TSUNAMI INUNDATION MODELING
}

\author{
Deniz Velioglu Sogut, Stony Brook University, deniz.velioglusogut@stonybrook.edu \\ Ahmet Cevdet Yalciner, Middle East Technical University, yalciner@metu.edu.tr
}

\section{ABSTRACT}

Bottom friction is an important parameter in tsunami inundation and should be included in the numerical simulations in order to reach reliable results. This study shows that smaller friction leads to larger runup values in the simulations and the runup distance of large amplitude waves is more friction sensitive. The analyses are conducted using FLOW 3D, a threedimensional numerical model efficient in solving free surface flows, and using three experimental benchmark problems, which are commonly used to validate numerical models in coastal engineering.

\section{EXPERIMENTAL BENCHMARK PROBLEM 1}

Benchmark problem 1 (BMP 1) investigates the runup of solitary waves on a 1:19.85 sloping beach (Figure 1). The description of experimental apparatus as well as the experimental data are given in the study of Synolakis (1986) in detail.

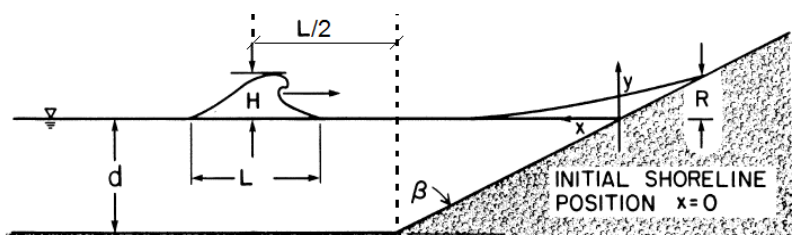

Figure 1 - A definition sketch of BMP 1 (Synolakis, 1986)

\section{EXPERIMENTAL BENCHMARK PROBLEM 2}

After the 1992 Flores tsunami, an unexpectedly large tsunami runup height was observed in the lee side of conical Babi Island. BMP 2 is composed of physical model studies carried out to provide a better understanding of the physical phenomena (Figure 2).

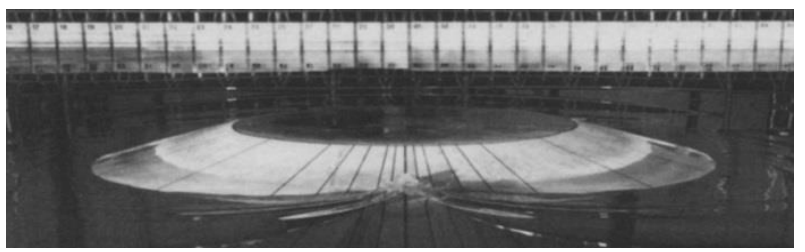

Figure 2 - BMP 2 experimental setup (Briggs et al., 1995)

\section{EXPERIMENTAL BENCHMARK PROBLEM 3}

Cox et al. (2008) designed a hydraulic model to study tsunami flow over and around macro-roughness to observe the role of building shape and density on tsunami inundation (Figure 3). BMP 3 provides the dataset of his experiments and is also Benchmark Problem 2 of the 2015 National Tsunami Hazard Mitigation Program (NTHMP) workshop, which was held in Portland, U.S (Velioglu, 2017).

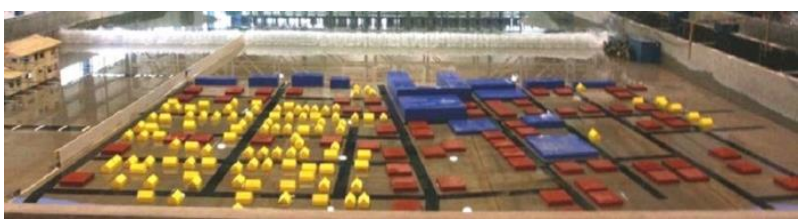

Figure 3 - BMP 3 experimental setup (Cox et al., 2008)

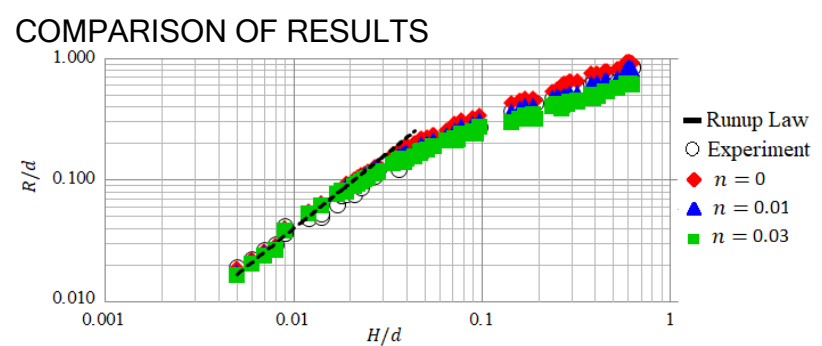

Figure 4 - BMP1: Effect of friction on wave runup

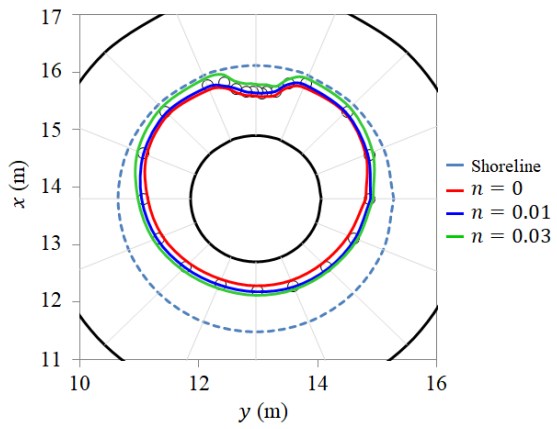

Figure 5 - BMP 2: Runup predictions around the conical island according to different Manning's roughness coefficients for a large amplitude solitary wave

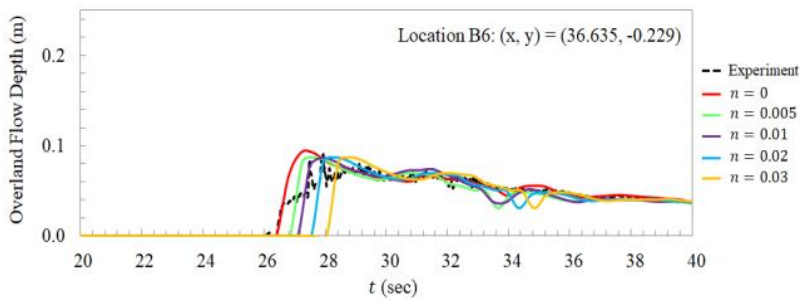

Figure 6 - BMP 3: Comparison of predicted and measured overland flow depth for a landward location

The results show that bottom friction is very effective on the wave runup height and wave propagation distance on land. Therefore, the bottom characteristics of the study area should be determined before developing reliable tsunami mitigation strategies based on tsunami numerical modeling.

\section{ACKNOWLEDGEMENTS}

Turkish branch of Flow Sciences, Inc. is acknowledged.

\section{REFERENCES}

Synolakis (1986): The Runup of Long Waves, Ph.D. Thesis, California Institute of Technology, USA.

Briggs, Synolakis, Harkins, Green (1995): Laboratory Experiments of Tsunami Runup on a Circular Island, PAGEOPH, 144.

Velioglu (2017): Advanced Two- and Three-Dimensional Tsunami Models: Benchmarking and Validation, Ph.D. Thesis, Middle East Technical University, Turkey.

Cox, Tomita, Lynett, Holman (2008): Tsunami Inundation with Macroroughness in the Constructed Environment, Proceedings of 31st International Conference on Coastal Engineering, ASCE, pp. 1421-1432. 